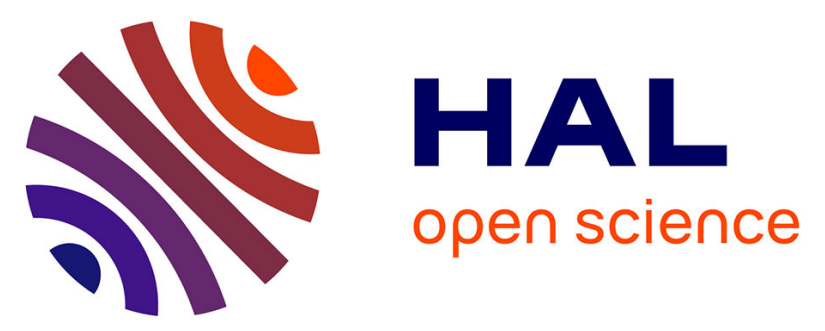

\title{
Induced Circular Dichroism in Phosphine Gold(I) Aryl Acetylide Urea Complexes through Hydrogen-Bonded Chiral Co-Assemblies
}

Julien Dubarle-Offner, Jamal Moussa, Hani Amouri, Benjamin Jouvelet, Laurent Bouteiller, Matthieu Raynal

\section{To cite this version:}

Julien Dubarle-Offner, Jamal Moussa, Hani Amouri, Benjamin Jouvelet, Laurent Bouteiller, et al.. Induced Circular Dichroism in Phosphine Gold(I) Aryl Acetylide Urea Complexes through HydrogenBonded Chiral Co-Assemblies. Chemistry - A European Journal, 2016, 22 (12), pp.3985-3990. 10.1002/chem.201504441. hal-01318173

\section{HAL Id: hal-01318173 https://hal.sorbonne-universite.fr/hal-01318173}

Submitted on 19 May 2016

HAL is a multi-disciplinary open access archive for the deposit and dissemination of scientific research documents, whether they are published or not. The documents may come from teaching and research institutions in France or abroad, or from public or private research centers.
L'archive ouverte pluridisciplinaire HAL, est destinée au dépôt et à la diffusion de documents scientifiques de niveau recherche, publiés ou non, émanant des établissements d'enseignement et de recherche français ou étrangers, des laboratoires publics ou privés. 


\title{
Induced circular dichroism in phosphine gold(I) arylacetylide urea complexes via hydrogen-bonded chiral co-assemblies
}

\author{
Julien Dubarle-Offner, ${ }^{[a]}$ Jamal Moussa ${ }^{[a]}$ Hani Amouri, ${ }^{\left[{ }^{[a]}\right.}$ Benjamin Jouvelet,${ }^{[a]}$ Laurent Bouteiller, ${ }^{[a]}$ \\ and Matthieu Rayna ${ }^{\star[a]}$
}

\begin{abstract}
Phosphine gold(I) arylacetylide complexes equipped with a central bis-urea moiety form 1D hydrogen-bonded polymeric assemblies in solution which do not display any optical activity. Chiral co-assemblies are formed by simple addition of an enantiopure (metal-free) complementary monomer. Although exhibiting an intrinsically achiral linear geometry, the gold(I) arylacetylide fragment is located in the chiral environment displayed by the hydrogen-bonded co-assemblies as demonstrated by induced circular dichroism (ICD).
\end{abstract}

Inducing chirality to metal complexes, ${ }^{[1]}$ nanoparticles ${ }^{[2]}$ and surface $^{[3]}$ is a central topic of chemical sciences motivated by important applications in the fields of chiral recognition, sensing, and catalysis. Notably, non-covalent interactions have been designed to place intrinsically achiral metal complexes in the chiral environment provided by various types of chiral species. ${ }^{[4]}$ Chirality induction is usually confirmed by the presence of a Cotton effect in the spectral region in which only the metal complex absorbs. ${ }^{[5]}$ The observation of such an induced circular dichroism $^{[6]}$ (ICD) signal reflects the specific electronic charge distribution within the thus formed chiral supramolecular entities. Gold(I) species have attracted considerable attention since the discovery of their catalytic and spectroscopic properties in solution and their potential use in a wide range of applications. ${ }^{[7]}$ However, since gold(I) has a known preference for a linear coordination geometry, the induction of chirality in gold(I) complexes is actually a non-trivial task. In the realm of asymmetric catalysis, an effective degree of enantioinduction is observed only for a few classes of chiral covalent ligands or anions. ${ }^{[8]}$ Alternatively, ICD signals have been observed for achiral gold complexes embedded into chiral surfactants ${ }^{\left[{ }^{[9]}\right.}$ or self-assembled within a semicrystalline chiral organized structure. ${ }^{[10]}$ Obviously, the incorporation of gold complexes in other chiral matrices can offer interesting alternatives. ${ }^{[11]}$

Notably, chiral supramolecular polymers constitute robust platforms for chirality transfer and amplification. ${ }^{[12]}$ Supramolecular polymers are often in dynamic exchange and co-polymers can be prepared by simply mixing different types of complementary monomers. Since the chiral information is

[a] Dr. Julien Dubarle-Offner, Dr. Jamal Moussa, Dr. Hani Amouri, Dr. Benjamin Jouvelet, Dr. Laurent Bouteiller, Dr. Matthieu Raynal Sorbonne Universités, UPMC Univ Paris 06,

CNRS, Institut Parisien de Chimie Moléculaire,

4 Place Jussieu, F-75005 Paris, France.

E-mail:matthieu.raynal@upmc.fr

hani.amouri@upmc.fr

Supporting information for this article is given via a link at the end of the document. transferred (and possibly amplified) along the polymeric backbone, co-polymers with a strong helical bias are formed which are composed of two types of monomers: the monomer bearing the chiral information (commonly called the sergeant) and the achiral monomer (the soldier). Up to now, sergeantsand-soldiers experiments have been mostly conducted with structurally-similar monomers in the purpose of probing the chirality amplification properties of supramolecular polymers. ${ }^{[4 \mathrm{e}, 12]}$

By adapting the sergeants-and-soldiers principle, we design a new strategy for the incorporation of metal complexes in a dynamic and modular chiral environment in solution. Onedimensional (1D) co-assemblies are targeted which contain sergeants and soldiers that differ not only by their chiral nature but also by the functionality located in their side chain. More precisely, we investigate mixtures containing: i) a bis-urea monomer bearing only the chiral information (the sergeant) and ii) a metal-functionalized bis-urea monomer (the soldier). The two urea moieties, connected through an aromatic spacer, constitute a well-known self-complementary hydrogen-bonded unit for the assembly of 1D supramolecular polymers in solution. ${ }^{[13]}$ Also, the co-assemblies formed by structurallysimple, non metal-functionalized, sergeants and soldiers are chiral and display strong chirality amplification effects. ${ }^{[14]}$ We expect that the intrinsically achiral metal fragment, located at the periphery of the co-assemblies, will be a reporter of the chirality displayed by the central supramolecular helices. The formation of such metal-functionalized co-assemblies seems particularly attractive since: it would allow to independently control i) the electronic characteristics of the metal complex soldier and ii) the degree of chirality induction/amplification within the coassemblies through the design of a metal-free sergeant.

Herein we describe the proof-of-principle of our strategy using racemic gold complexes as the soldiers and enantiopure monomers as the sergeants. The observation of an ICD signal clearly demonstrates that the gold arylacetylide complexes are located in the chiral environment displayed by the co-assemblies. Our investigated gold(I) complexes $\mathbf{1} \cdot \mathrm{AuPPh}_{3}$ and $\mathbf{1} \cdot \mathrm{AuPC}_{3}$ (Chart 1) contain the following structural elements: i) a central bis-urea moiety as associative unit, ii) a racemic 2-ethylhexyl group on one side to impart solubility, iii) a neutral phosphine gold(I) complex on the other side and iv) a rigid 4phenylacetylene linker in order to prevent interactions between the urea and gold complex units. Neutral metal complexes are particularly adapted for this study since anions have strong affinity for urea functions as exemplified by the well-known anion sensing properties displayed by urea derivatives. ${ }^{[15]}$

$\mathbf{1} \cdot \mathrm{AuPPh}_{3}$ and $\mathbf{1} \cdot \mathrm{AuPCy}_{\mathbf{3}}$ were obtained by reacting $\mathbf{1} \cdot \mathbf{H}$ with $\left[\mathrm{AuCl}\left(\mathrm{PPh}_{3}\right)\right]$ and $\left[\mathrm{AuCl}\left(\mathrm{PCy}_{3}\right)\right]$ respectively, in the presence of $\mathrm{Cs}_{2} \mathrm{CO}_{3}$ and were purified by precipitation in methanol. Analytical data of $\mathbf{1 \cdot A u P P h} \mathbf{A}_{3}$ and $\mathbf{1} \cdot \mathrm{AuPCy}_{\mathbf{3}}$ are in accordance 


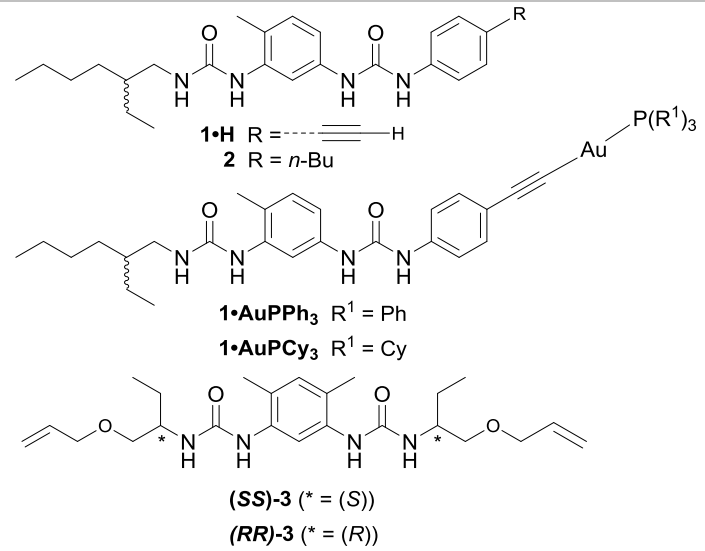

Chart 1 Structure of the bis-urea derivatives.

with the structures drawn in Chart 1 (see the Supporting Information). In particular the ${ }^{31} \mathrm{P}\left\{{ }^{1} \mathrm{H}\right\}$ NMR spectra of the gold(I) acetylide bis-urea complexes recorded in $\left[\mathrm{D}_{6}\right]$-dmso show a singlet at ca. $\delta 41.8 \mathrm{ppm}$ and $57.3 \mathrm{ppm}$ respectively. To the best of our knowledge, 1·AuPPh $\mathbf{A}_{3}$ and $\mathbf{1} \cdot \mathrm{AuPCy}_{3}$ constitute the first examples of metal complexes containing a bis-urea moiety. ${ }^{[16]}$ 1.AuPPh ${ }_{3}$ and 1.AuPCy $y_{3}$ proved to be well soluble in THF, $\mathrm{CH}_{2} \mathrm{Cl}_{2}$ and $\mathrm{CHCl}_{3}$ but very poorly soluble in toluene and cyclohexane. According to these solubility tests, (SS)-3 and $(\boldsymbol{R} \boldsymbol{R})$-3 were chosen as the enantiopure complementary monomers since these bis-ureas are expected to strongly selfassociate even in relatively polar solvents. ${ }^{[17]}$

Indeed, Fourier Transform Infrared (FT-IR) spectroscopy and Small Angle Neutron Scattering (SANS) experiments confirm that (SS)-3 forms long and rigid urea-bonded self-assemblies in $\mathrm{CH}_{2} \mathrm{Cl}_{2} / \mathrm{THF}$ 9:1 at mM concentrations (Figure S.1) ${ }^{[18]}$ Also, the self-assemblies of (SS)-3 and (RR)-3 display mirror image CD spectra (Figure S.2). A strong Cotton effect is observed in the region corresponding to aromatic and urea chromophores at $\lambda_{\text {abs }}=232 \mathrm{~nm}\left(|\Delta \varepsilon|=28.0\right.$ L. mol $\left.{ }^{-1} . \mathrm{cm}^{-1}\right)$ and a weak CD signal is also found above $260 \mathrm{~nm}\left(|\Delta \varepsilon| \approx 0.5 \mathrm{~L} \cdot \mathrm{mol}^{-1} . \mathrm{cm}^{-1}\right.$ at $\left.\lambda_{a b s}=295 \mathrm{~nm}\right)$ These signals almost totally disappear in ethanol, a strong hydrogen-bond competitor, confirming that the CD activity of (SS)-3 and $(\boldsymbol{R R})-\mathbf{3}$ is related to the supramolecular chirality of the assemblies.

The self-assembly properties of $\mathbf{1} \cdot \mathrm{AuPPh}_{3}$ and $\mathbf{1} \cdot \mathrm{AuPC}_{3}$ in $\mathrm{CHCl}_{3}$ was also probed by means of FT-IR and SANS analyses. 1.AuPPh 3 and 2, ${ }^{[19]}$ a structurally-related bis-urea lacking the phosphine gold $(\mathrm{I})$ acetylide fragment, ${ }^{[20]}$ present very similar FTIR spectra with a broad $\mathrm{NH}$ band at ca. $3300 \mathrm{~cm}^{-1}$ and a $\mathrm{CO}$ band at ca. $1637 \mathrm{~cm}^{-1}$ indicative of the presence of urea-bonded assemblies (Figure 1). ${ }^{[21]}$ In both cases, small bands related to free $\mathrm{NH}$ and $\mathrm{CO}$ functions can also be detected (at ca. 3425 $\mathrm{cm}^{-1}$ and $1700 \mathrm{~cm}^{-1}$ respectively) which correspond to the free urea groups located at the extremities of the assemblies and/or to monomers. The same bands are observed for $1 \cdot \mathbf{A u P C}_{3}$ but the proportion of free urea groups is higher demonstrating that the assemblies formed by $\mathbf{1} \cdot \mathrm{AuPC}_{3}$ are shorter than those of 1.AuPPh ${ }_{3}$ as a probable result of higher steric repulsion between consecutive Cy groups in the polymeric structure. Moreover, $\mathbf{1} \cdot \mathrm{AuPPh}_{3}$ forms discrete cylindrical objects in solution with a radius of $10.1 \AA$ and a length $>250 \AA$ as demonstrated by SANS analysis performed in $\mathrm{CD}_{2} \mathrm{Cl}_{2} / \mathrm{THF}-\mathrm{d}_{8}$ (9:1 ratio, Figure S.1). Taken all together, these analyses clearly indicate that the phosphine gold acetylide fragment located at the extremity of $\mathbf{1} \cdot \mathrm{AuPPh}_{3}$ and $\mathbf{1} \cdot \mathrm{AuPCy}_{3}$ does not prevent the

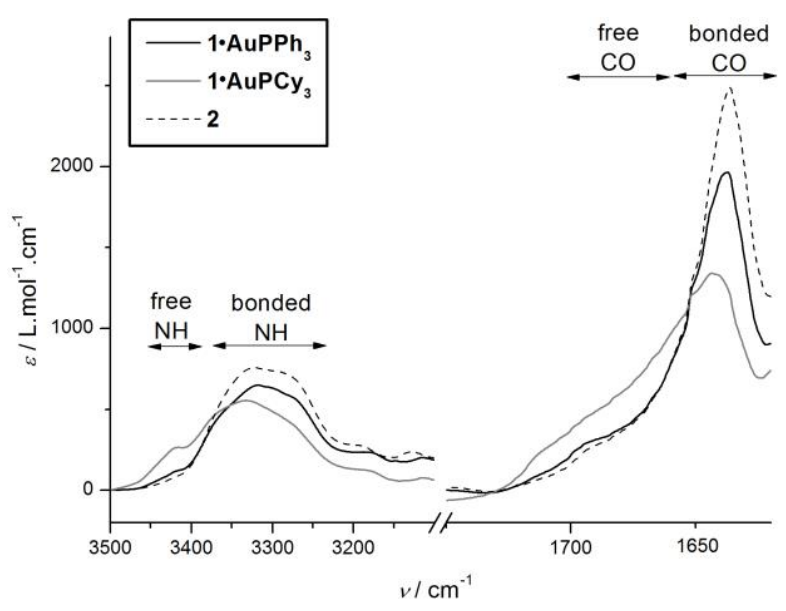

Figure $1 \mathrm{FT}$-IR spectra of 1·AuPPh, $1 \cdot \mathrm{AuPCy}_{3}$ and $2\left(\mathrm{CHCl}_{3}, 6 \mathrm{mM}\right)$. Zoom on the $\mathrm{NH}$ and $\mathrm{CO}$ bands.

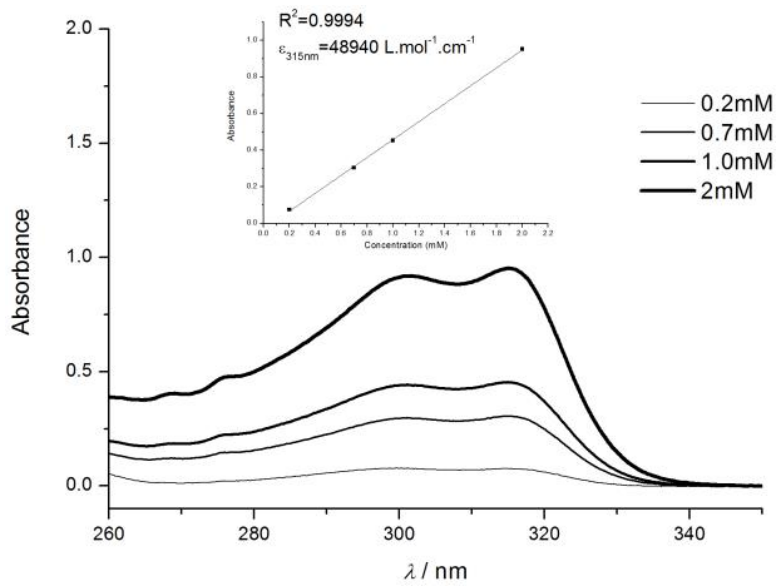

Figure $2 \mathrm{UV}$ absorption spectra of $1 \cdot \mathrm{AuPPh}_{3}\left(-11^{\circ} \mathrm{C}\right)$ in $\mathrm{CH}_{2} \mathrm{Cl}_{2} / \mathrm{THF}$ (9:1 ratio) at various concentrations. Inset: linear fitting of the absorbance (measured at $\lambda=315 \mathrm{~nm}, 0.1 \mathrm{~mm}$ path length) versus the concentration.

association of the central bis-urea units.

We then verified whether the gold(I) acetylide fragment is involved in the self-assembly process of $\mathbf{1 \cdot A u P P h}$ and 1.AuPCy. We observed no shifts or shape changes for the absorption bands upon varying the concentration (from 0.2 to 2 $\mathrm{mM}$, Figure 2). This is in contrast to literature examples in which the metal acetylide moiety is involved in the aggregation process through $\pi-\pi$ stacking, metal-metal and/or solvophobic

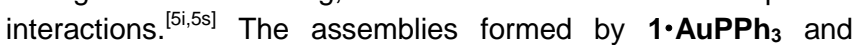
1.AuPCy $\mathrm{A}_{3}$ constitute rare examples of gold complexes aggregates in which neither the gold centre nor its connected ligands play a role in the association process. ${ }^{[22]}$

1-AuPPh $\mathbf{P}_{\mathbf{3}}$ and 1.AuPCy $\mathbf{y}_{\mathbf{3}}$ exhibit similar UV absorption spectra in $\mathrm{CH}_{2} \mathrm{Cl}_{2} / \mathrm{THF}$ 9:1 (Figure 3). Below $260 \mathrm{~nm}$, both UV spectra show a broad band corresponding to aromatic and urea chromophores (Figure 3). This high-energy absorption band is more intense in the case of $\mathbf{1 \cdot A u P P h}$ as the $\mathrm{PPh}_{3}$ moiety absorbs in this region. ${ }^{[23]}$ At lower energies, both complexes exhibit structured absorption bands ( $\lambda_{\text {abs }}$ at ca. 280,300 and 315 $\mathrm{nm}$ ) which closely resemble those displayed by the mono-urea gold(I) acetylide complexes studied by Chao and co-workers. ${ }^{[16 a]}$ Vibrational spacings of ca. $1700 \mathrm{~cm}^{-1}$ and $2200 \mathrm{~cm}^{-1}$ can be ascribed to $v(\mathrm{C}=\mathrm{O})$ and $v(\mathrm{C} \equiv \mathrm{C})$, respectively (Table $\mathrm{S} .1$ ). Accordingly, these absorption bands correspond to ${ }^{1}\left(\pi \rightarrow \pi^{\star}\right)$ transitions involving the carbonyl group of the urea functions and the acetylenic unit of the acetylide ligand. The metal-perturbed intraligand $(\mathrm{IL})\left[\pi \rightarrow \pi^{*}(\mathrm{C} \equiv \mathrm{C})\right]$ transition has possibly some metal- 


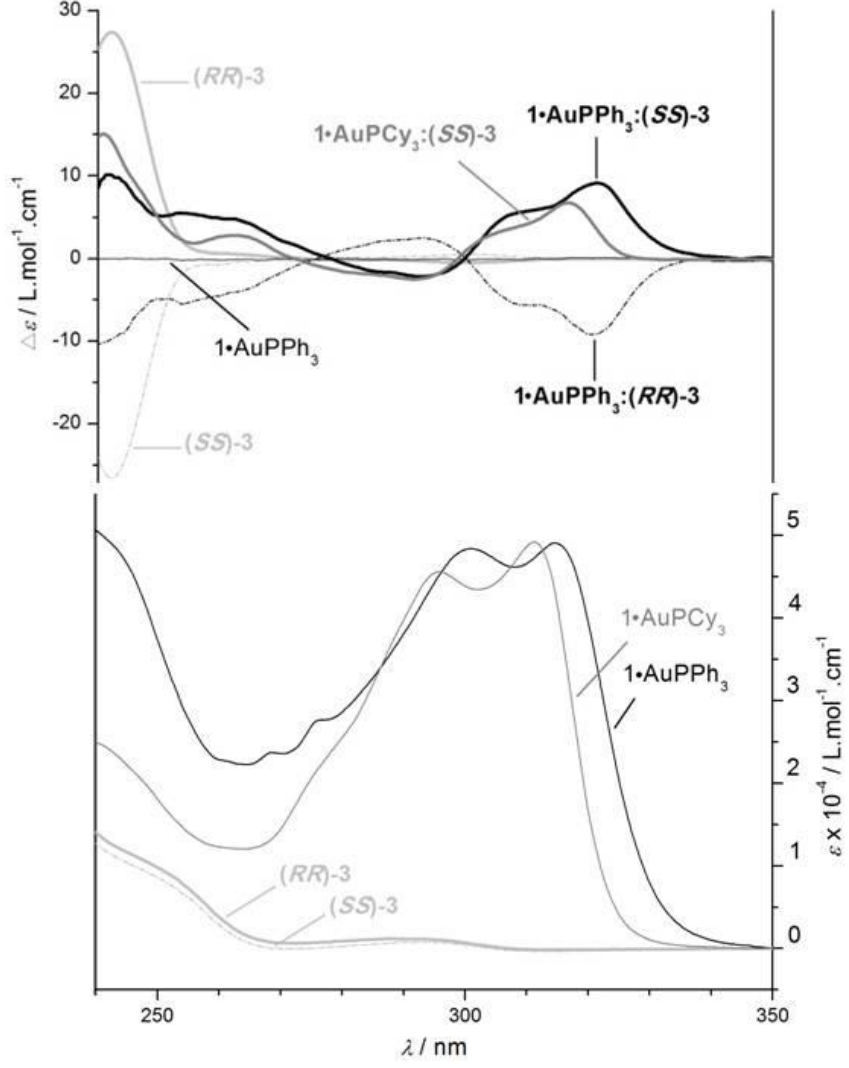

Figure 3 Top: CD spectra (top) of the 1:1 mixtures of the gold complexes and the sergeants, of (SS)-3, of $(\boldsymbol{R R})-\mathbf{3}$ and of $\mathbf{1} \cdot \mathrm{AuPPh}_{\mathbf{3}}\left(1 \mathrm{mM}, \mathrm{CH}_{2} \mathrm{Cl}_{2} / \mathrm{THF}\right.$ $\left.9: 1,-11^{\circ} \mathrm{C}\right)$. For the mixtures, $\Delta \varepsilon=\theta / 32980 \times / \times C$ where $\theta$ is the measured ellipticity in mdeg, $l$ is the path length in $\mathrm{cm}$ and $c$ is the concentration in gold complex in mol. $\mathrm{L}^{-1}$. Bottom: UV absorption spectra of gold complexes and sergeants. The CD spectrum of $\mathbf{1} \cdot \mathrm{AuPCy}_{3}$ and the UV spectra of the mixtures have been omitted for clarity (see Figure S.3). Color figures in SI.

to-ligand charge transfer (MLCT) character. The low-energy absorption band of $\mathbf{1} \cdot \mathrm{AuPPh}_{\mathbf{3}}$ is slightly bathochromically shifted (3 nm) compared to $\mathbf{1 \cdot A u P C y _ { 3 }}$ presumably as a result of the different influence of $\mathrm{PPh}_{3}$ and $\mathrm{PCy}_{3}$ on the metal-perturbed intraligand (IL) $\left[\pi \rightarrow \pi^{*}(\mathrm{C} \equiv \mathrm{C})\right]$ transition. ${ }^{[16 a, 23-24]}$ As expected given that $\mathbf{1} \cdot \mathrm{AuPPh}_{\mathbf{3}}$ and $\mathbf{1} \cdot \mathrm{AuPC}_{\mathbf{3}}$ are racemates, their selfassemblies do not show any optical activity (CD spectra, Figures 3 and S.3). ${ }^{[25]}$

We next probed the co-assembly properties of soldiers 1.AuPPh ${ }_{3}$ or $\mathbf{1} \cdot \mathrm{AuPCy}_{\mathbf{3}}$ with the chiral sergeants $\mathbf{3}$. We prepared $1 \mathrm{mM}$ solutions of gold complexes $\left(\mathbf{1} \cdot \mathbf{A u P P h}_{\mathbf{3}}\right.$ or 1·AuPCy $\mathbf{y}_{3}$ ) and sergeants ((SS)-3 or (RR)-3) in $\mathrm{CH}_{2} \mathrm{Cl}_{2} / \mathrm{THF}(9: 1$ ratio), a solvent combination in which all partners are soluble, and mixed them in a 1:1 ratio. ${ }^{[26]}$ The CD spectra of the different mixtures clearly reveal that the soldiers and sergeants form coassemblies. Indeed, the CD spectra of mixtures of the gold complexes with (SS)-3 show CD signals which totally differ from that of (SS)-3 (Figures 3 and S.3). Their CD spectra exhibit: i) a positive peak in the $230-260 \mathrm{~nm}$ region, a region in which (SS)-3 exhibits a strong negative Cotton effect and in which (SS)-3, 1.AuPPh ${ }_{3}$ and 1.AuPCy $\mathbf{y}_{3}$ strongly absorb, and ii) a weak negative signal followed by a positive signal in the $270-340 \mathrm{~nm}$ region in which (SS)-3 only shows a very weak positive peak. Below $270 \mathrm{~nm}$, the sergeants-and-soldiers co-assemblies and the sergeant self-assemblies exhibit CD signals of opposite signs. Even though the origin of this inversion is difficult to establish given that both aromatic and urea chromophores

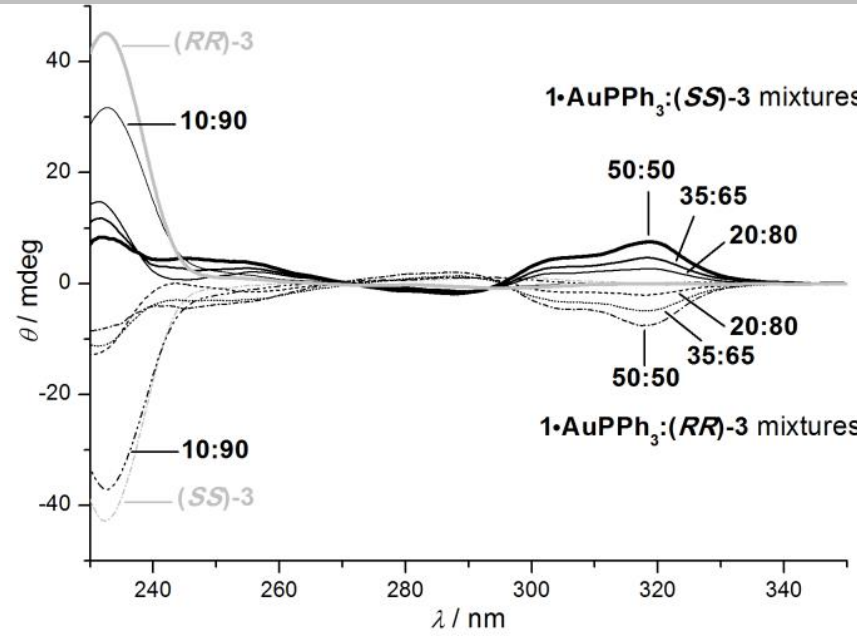

Figure $4 \mathrm{CD}$ spectra of the mixtures of $1 \cdot \mathrm{AuPPh}_{3}$ and (SS)-3 or of the mixtures of $\mathbf{1} \cdot \mathrm{AuPPh}_{3}$ and $(\boldsymbol{R} \boldsymbol{R}) \mathbf{- 3}$ at different ratios $\left(1 \mathrm{mM}, \mathrm{CH}_{2} \mathrm{Cl}_{2} / \mathrm{THF}\right.$ $\left.9: 1,-11^{\circ} \mathrm{C}\right)$. Color figures in $\mathrm{SI}$.

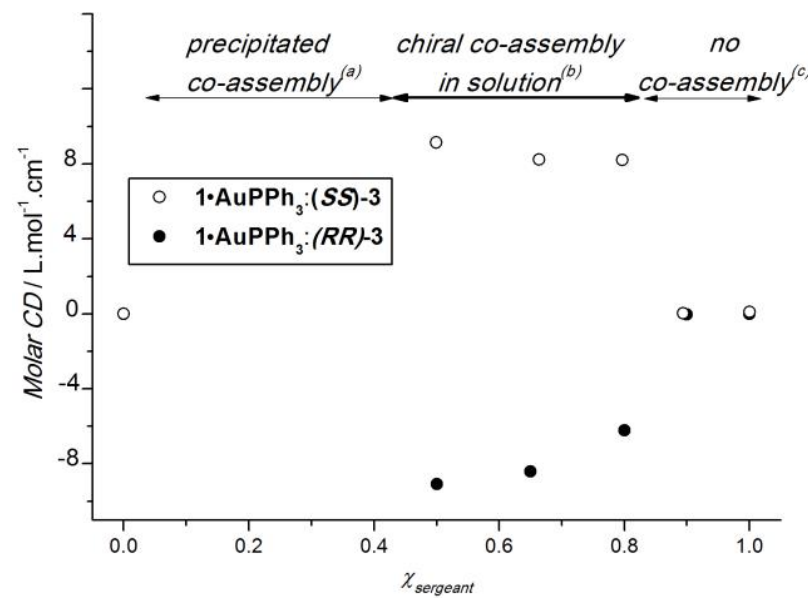

Figure 5 Molar $\mathrm{CD}(\Delta \varepsilon$, measured at $318.5 \mathrm{~nm})$ vs the ratio of sergeant in the mixtures. $\Delta \varepsilon=\theta / 32980 \times / \times c$ where $\theta$ is the measured ellipticity at $318.5 \mathrm{~nm}$ in mdeg, $l$ is the path length in $\mathrm{cm}$ and $c$ is the concentration in gold complex in mol. $L^{-1} \cdot \chi_{\text {sergeant }}=[$ sergeant $] /([$ sergeant $]+[$ gold complex $])$. (a) Social self-sorting between $\mathbf{1} \cdot \mathrm{AuPPh}_{3}$ and the sergeant but determination of the molar CD values are precluded by the heterogeneous nature of the mixtures. (b) Social selfsorting between 1.AuPPh and the sergeant in solution. (c) Narcissistic selfsorting i.e. the individual assemblies formed by $\mathbf{1} \cdot \mathbf{A u P P h}_{3}$ and the sergeant do not co-assemble. ${ }^{[27]}$

absorb in this region, this observation clearly reveals that the bis-urea units of the sergeants-and-soldiers co-assemblies are located in a chiral environment.

Most importantly the bands above $270 \mathrm{~nm}$ in the CD spectra of the sergeants-and-soldiers mixtures are related to the transitions observed in the electronic spectra of the gold complexes but not in that of the sergeant (Figure 3). The presence of this ICD signal demonstrates that the peripheral gold arylacetylide fragment of $\mathbf{1} \cdot \mathrm{AuPPh}_{3}$ and $\mathbf{1} \cdot \mathrm{AuPCy}_{3}$ are located in the chiral environment displayed by the sergeants-and-soldiers coassemblies. ${ }^{[28]}$

The ICD signal displayed by $1: 1$ mixture of $\mathbf{1} \cdot \mathrm{AuPPh}_{3}$ and (SS)-3 $\left(\Delta \varepsilon_{318.5 \mathrm{~nm}} \approx 9 \mathrm{~L} \mathrm{~mol}^{-1} . \mathrm{cm}^{-1}\right)$ is slightly stronger than that of the $1: 1$ mixture of $1 \cdot \mathrm{AuPCy}_{3}$ and (SS)-3 $\left(\Delta \varepsilon_{314 \mathrm{~nm}} \approx 6.5 \mathrm{~L} \cdot \mathrm{mol}^{-1} \cdot \mathrm{cm}^{-1}\right)$. It might be related to the better association properties of 1.AuPPh ${ }_{3}$ (vide supra) and/or to the efficiency of the chirality transfer ${ }^{[29]}$ Moreover, the CD spectra of $\mathbf{1} \cdot \mathrm{AuPPh}_{3}:(\mathbf{S S})-\mathbf{3}$ and 1-AuPPh ${ }_{3}:(R R)-3$ are mirror images showing that the sergeant can be used to invert the chirality induced to the gold arylacetylide fragment (Figures 3 and 4). 
We found out that the chirality induced to the intrinsically achiral gold acetylide fragment can be altered in a reversible way by varying the temperature. The ICD signal of the co-assemblies between 1.AuPCy $\mathbf{y}_{\mathbf{3}}$ and (SS)-3 (1:1 mixture) has a maximum intensity at $-10^{\circ} \mathrm{C}$ and $-5^{\circ} \mathrm{C}$ and then gradually decreases, yet a residual ICD signal is still present at $20^{\circ} \mathrm{C}$ (Figure S.5). More importantly, the initial ICD signal is restored upon returning to the initial temperature $\left(-10^{\circ} \mathrm{C}\right)$.

Finally, we probed the influence of the sergeant on the coassembly process and on the efficiency of the chirality transfer by preparing mixtures of $\mathbf{1 \cdot A u P P h}$ and sergeant ((SS)-3 or $(\boldsymbol{R R})-3)$ at different ratios. We surprisingly found that the mixtures containing more than $50 \%$ of gold complex precipitated. Since mixtures are prepared from homogeneous $1 \mathrm{mM}$ mother solutions, this observation suggests that the co-assemblies formed but were poorly soluble under these experimental conditions. The CD spectra of the mixtures with a lower amount of gold complex $(\leq 50 \%)$ are shown in Figure 4 . The spectra of the mixtures with $10 \%$ of $\mathbf{1} \cdot \mathrm{AuPPh}_{3}$ resemble those of pure sergeants with a strong Cotton effect at $\lambda_{\mathrm{abs}}=232 \mathrm{~nm}$ and no signal in the 270-340 $\mathrm{nm}$ region suggesting that the co-assembly process is hampered in these cases i.e. the individual supramolecular polymers formed by $\mathbf{1} \cdot \mathrm{AuPPh}_{3}$ and (SS)-3 (or $(\boldsymbol{R R})-3)$ do not co-assemble. In contrast, the mixtures at $20 \%$ and $35 \%$ of $\mathbf{1} \cdot \mathbf{A u P P h}_{3}$ exhibit a CD signature which is similar to the one displayed by the mixture containing $50 \%$ of $\mathbf{1 \cdot A u P P h}$ described above (Figure 3 ) indicating the formation of chiral coassemblies.

The molar CD values, defined as the ellipticity normalized by the soldier concentration (1・AuPPh ), can be plotted as a function of the ratio of sergeant in the mixture (Figure 5 ). For mixtures for which co-assembly is observed in solution $\left(0.5 \leq \chi_{\text {sergeant }} \leq 0.8\right)$, it is interesting to note that the molar $C D$ values remain approximately constant upon increasing the amount of sergeant. This non-proportional relationship between the molar $C D$ value and the amount of sergeant suggests that the co-assemblies display chirality amplification effects. However, the precipitation of the co-polymers with low sergeant ratio prevents the determination of the minimum amount of sergeant required to get fully chiral co-assemblies. Moreover, as mentioned above, no co-assembly forms for mixtures containing high amount of sergeant. These data indicate that the formation of sergeantsand-soldiers co-assemblies strongly depends on the respective content of gold complex and sergeant present in solution (Figure $5)$.

In summary, our results clearly demonstrate that phosphine gold(I) arylacetylide fragments, albeit exhibiting an intrinsically achiral linear geometry, can be located in the chiral environment displayed by sergeants-and-soldiers co-assemblies. The chirality induced to the gold acetylide fragment can be inverted by using sergeant enantiomers and altered by varying the temperature holding promising applications in the fields of asymmetric catalysis. ${ }^{[59,30]}$ The strategy is not limited to gold complexes but can be extended to metal complexes displaying various coordination modes and to other types of functionalized coassemblies.

\section{Experimental Section}

Sample preparation and CD analyses of mixtures of the gold complex and the sergeant: $1.0 \mathrm{mM}$ stock solutions of the gold complex and the sergeant in $\mathrm{CH}_{2} \mathrm{Cl}_{2} / \mathrm{THF}$ 9:1 were mixed to the desired ratio and heated to b.p. of the solvent. Samples were weighed and corrected for solvent loss when necessary. Samples were briefly heated again a few minutes before $C D$ analyses. $C D$ measurements were performed on a Jasco J-1500 spectrometer equipped with a Peltier thermostated cell holder and Xe laser (lamp UXL-150S) in $0.5 \mathrm{~mm}$ dismountable quartz cells. Data was recorded at $-11^{\circ} \mathrm{C}$ since a more intense signal was observed at this temperature compared to room temperature. For CD experiments at various temperatures see Figure S.5. The following parameters were used: $20 \mathrm{~nm} \cdot \mathrm{min}^{-1}$ sweep rate, $0.05 \mathrm{~nm}$ data pitch, 1.0 $\mathrm{nm}$ bandwidth and 3 accumulations. The obtained signals were processed as follow: solvent and cell contribution was subtracted and the signals were smoothed (Savitzky-Golay method). For all samples, linear dichroism (LD) contribution was negligible $(\Delta \mathrm{LD}<0.005 \mathrm{dOD})$. For more experimental details, see the Supporting Information.

\section{Acknowledgements}

Support from the LabEx MiChem part of French state funds managed by the ANR within the Investissements d'Avenir programme under reference ANR-11-IDEX-0004-02 is acknowledged. We thank François Boué (LLB, Saclay) for assistance with SANS experiments, Nicolas Vanthuyne (iSm2, Marseille) for chiral HPLC analyses and Claire Troufflard (IPCM, Paris) for NMR analyses.

Keywords: Induced Circular Dichroism - Supramolecular polymers Sergeants-and-soldiers principle $\bullet$ Gold complexes $\bullet$ Chirality transfer

[1] a) X. K. Fang, T. M. Anderson, C. L. Hill, Angew. Chem. 2005, 117 3606-3610; Angew. Chem. Int. Ed. 2005, 44, 3540-3544; b) H. Amouri, M. Gruselle, Chirality in Transition Metal Chemistry: Molecules, Supramolecular assemblies \& Materials, Wiley: Chichester, UK., 2008; c) J. Crassous, Chem. Soc. Rev. 2009, 38, 830-845; d) J. Crassous, Chem. Commun. 2012, 48, 9684-9692; e) H. Miyake, H. Tsukube, Chem. Soc. Rev. 2012, 41, 6977-6991.

[2] a) C. Noguez, I. L. Garzon, Chem. Soc. Rev. 2009, 38, 757-771; b) S. Knoppe, T. Burgi, Acc. Chem. Res. 2014, 47, 1318-1326.

[3] F. Ronci, R. Gatti, G. Caponi, S. Colonna, G. Galeotti, D. Catone, S Turchini, T. Prosperi, N. Zema, A. Palma, P. Gori, G. Contini, Surf. Sci. 2014, 629, 41-47.

[4] a) G. A. Hembury, V. V. Borovkov, Y. Inoue, Chem. Rev. 2008, 108, 1 73; b) A. J. Boersma, R. P. Megens, B. L. Feringa, G. Roelfes, Chem Soc. Rev. 2010, 39, 2083-2092; c) T. R. Ward, Acc. Chem. Res. 2011 44, 47-57; d) M. V. Escarcega-Bobadilla, A. W. Kleij, Chem. Sci. 2012, 3, 2421-2428; e) M. H. Liu, L. Zhang, T. Y. Wang, Chem. Rev. 2015, 115, 7304-7397.

[5] For representative examples of ICD in metal complexes see: a) $R$ Lauceri, A. Raudino, L. M. Scolaro, N. Micali, R. Purrello, J. Am. Chem. Soc. 2002, 124, 894-895; b) V. Cantonetti, D. Monti, M. Venanzi, C. Bombelli, F. Ceccacci, G. Mancini, Tetrahedron Asymmetry 2004, 15 1969-1977; c) M. Balaz, M. De Napoli, A. E. Holmes, A. Mammana, K Nakanishi, N. Berova, R. Purrello, Angew. Chem. 2005, 117, 4074 4077; Angew. Chem. Int. Ed. 2005, 44, 4006-4009; d) N. Das, A Ghosh, O. M. Singh, P. J. Stang, Org. Lett. 2006, 8, 1701-1704; e) C Yu, K. H. Y. Chan, K. M. C. Wong, V. W. W. Yam, Proc. Natl. Acad. Sci. U.S.A. 2006, 103, 19652-19657; f) M. Ikeda, Y. Tanaka, T. Hasegawa Y. Furusho, E. Yashima, J. Am. Chem. Soc. 2006, 128, 6806-6807; g) T. Hasegawa, Y. Furusho, H. Katagiri, E. Yashima, Angew. Chem. 2007, 119, 5989-5992; Angew. Chem. Int. Ed. 2007, 46, 5885-5888; h) Y. Ishii, Y. Soeda, Y. Kubo, Chem. Commun. 2007, 2953-2955; i) T. Cardolaccia, Y. J. Li, K. S. Schanze, J. Am. Chem. Soc. 2008, 130, 2535-2545; j) R. Lauceri, G. F. Fasciglione, A. D'Urso, S. Marini, R. Purrello, M. Coletta, J. Am. Chem. Soc. 2008, 130, 10476-10477; k) T. Haino, H. Shio, R. Takano, Y. Fukazawa, Chem. Commun. 2009, 2481 2483; I) A. Y. Y. Tam, K. M. C. Wong, V. W. W. Yam, Chem. Eur. J. 2009, 15, 4775-4778; m) M. C. L. Yeung, K. M. C. Wong, Y. K. T Tsang, V. W. W. Yam, Chem. Commun. 2010, 46, 7709-7711; n) F. Helmich, C. C. Lee, A. P. H. J. Schenning, E. W. Meijer, J. Am. Chem. 
Soc. 2010, 132, 16753-16755; o) I. Occhiuto, G. De Luca, V. Villari, A Romeo, N. Micali, R. F. Pasternack, L. M. Scolaro, Chem. Commun 2011, 47, 6045-6047; p) M. C. L. Yeung, V. W. W. Yam, Chem. Eur. J. 2011, 17, 11987-11990; q) H. Ito, M. Ikeda, T. Hasegawa, Y. Furusho, E. Yashima, J. Am. Chem. Soc. 2011, 133, 3419-3432; r) F. Helmich, M. M. J. Smulders, C. C. Lee, A. P. H. J. Schenning, E. W. Meijer, J. Am. Chem. Soc. 2011, 133, 12238-12246; s) Y. J. Tian, E. W. Meijer, F. Wang, Chem. Commun. 2013, 49, 9197-9199; t) C. Po, Z. H. Ke, A. Y. Y. Tam, H. F. Chow, V. W. W. Yam, Chem. Eur. J. 2013, 19, 15735 15744; u) M. C. L. Yeung, V. W. W. Yam, Chem. Sci. 2013, 4, 2928 2935; v) H. Quu, J. B. Gilroy, I. Manners, Chem. Commun. 2013, 49, 42 44; w) K. Nonaka, M. Yamaguchi, M. Yasui, S. Fujiwara, T. Hashimoto, T. Hayashita, Chem. Commun. 2014, 50, 10059-10061; x) C. Y. S. Chung, S. Tamaru, S. Shinkai, V. W. W. Yam, Chem. Eur. J. 2015, 21 5447-5458.

[6] S. Allenmark, Chirality 2003, 15, 409-422.

[7] a) V. W. W. Yam, E. C. C. Cheng, Chem. Soc. Rev. 2008, 37, 18061813; b) J. C. Lima, L. Rodriguez, Chem. Soc. Rev. 2011, 40, 54425456 .

[8] Y. M. Wang, A. D. Lackner, F. D. Toste, Acc. Chem. Res. 2014, 47 889-901.

[9] A. Longo, D. Banerjee, D. Hermida-Merino, G. Portale, P. Calandra, V. T. Liveri, J. Phys. Chem. C 2015, 119, 18798-18807.

[10] K. Kawaguchi, T. Seki, T. Karatsu, A. Kitamura, H. Ito, S. Yagai, Chem. Commun. 2013, 49, 11391-11393.

[11] Supramolecular polymers and low molecular-mass organogelators have been used as templates for the preparation of chiral $A u$ nanoparticles: a) A. Guerrero-Martínez, B. Auguié, J. L. Alonso-Gómez, Z. Džolić, S. Gómez-Graña, M. Žinić, M. M. Cid, L. M. Liz-Marzán, Angew. Chem.2011, 123, 5613-5617; Angew. Chem. Int. Ed. 2011, 50 5499-5503; b) L. L. Zhu, X. Li, S. J. Wu, K. T. Nguyen, H. Yan, H Agren, Y. L. Zhao, J. Am. Chem. Soc. 2013, 135, 9174-9180; c) S. H. Jung, J. Jeon, H. Kim, J. Jaworski, J. H. Jung, J. Am. Chem. Soc. 2014, 136, 6446-6452.

[12] A. R. A. Palmans, E. W. Meijer, Angew. Chem. 2007, 119, 9106-9126; Angew. Chem. Int. Ed. 2007, 46, 8948-8968.

[13] B. Isare, S. Pensec, M. Raynal, L. Bouteiller, C. R. Chim., in press, DOI 10.1016/j.crci.2015.1006.1013

[14] a) B. Isare, M. Linares, L. Zargarian, S. Fermandjian, M. Miura, S Motohashi, N. Vanthuyne, R. Lazzaroni, L. Bouteiller, Chem. Eur. J. 2010, 16, 173-177; b) F. Rodriguez-Llansola, D. Hermida-Merino, B Nieto-Ortega, F. J. Ramirez, J. T. L. Navarrete, J. Casado, I. W Hamley, B. Escuder, W. Hayes, J. F. Miravet, Chem. Eur. J. 2012, 18 14725-14731; c) B. Jouvelet, B. Isare, L. Bouteiller, P. van der Schoot Langmuir 2014, 30, 4570-4575.

[15] a) V. Amendola, L. Fabbrizzi, L. Mosca, Chem. Soc. Rev. 2010, 39 3889-3915; b) A. F. Li, J. H. Wang, F. Wang, Y. B. Jiang, Chem. Soc Rev. 2010, 39, 3729-3745.

[16] For mono-ureas functionalized with a gold acetylide moiety see: a) Y. P. Zhou, M. Zhang, Y. H. Li, Q. R. Guan, F. Wang, Z. J. Lin, C. K. Lam, X. L. Feng, H. Y. Chao, Inorg. Chem. 2012, 51, 5099-5109; b) X. M. He, N. Y. Zhu, V. W. W. Yam, Dalton Trans. 2011, 40, 9703-9710.

[17] F. Ouhib, M. Raynal, B. Jouvelet, B. Isare, L. Bouteiller, Chem. Commun. 2011, 47, 10683-10685.

[18] A more precise description of the structure of the self-assemblies (monomer conformation and relative orientation within the polymeric structure) is not possible at this stage for the homopolymers and the copolymers.

[19] O. Colombani, L. Bouteiller, New. J. Chem. 2004, 28, 1373-1382.

[20] $\mathbf{1} \cdot \mathbf{H}$ is poorly soluble in chlorinated solvents.

[21] V. Simic, L. Bouteiller, M. Jalabert, J. Am. Chem. Soc. 2003, 125, 13148-13154.

[22] Z. Chen, D. Wu, X. Han, J. H. Liang, J. Yin, G. A. Yu, S. H. Liu, Chem Commun. 2014, 50, 11033-11035.

[23] V. W. W. Yam, K. L. Cheung, S. K. Yip, K. K. Cheung, J. Organomet. Chem. 2003, 681, 196-209.

[24] W. Lu, N. Y. Zhu, C. M. Che, J. Am. Chem. Soc. 2003, 125, 16081 16088.

[25] For spontaneous resolution of supramolecular helices formed from a racemate see: H. Cao, X. F. Zhu, M. H. Liu, Angew. Chem. 2013, 125 4216-4220; Angew. Chem. Int. Ed. 2013, 52, 4122-4126.
[26] $\mathrm{CH}_{2} \mathrm{Cl}_{2} / \mathrm{THF}$ 9:1 is a more competitive solvent for the gold complexes assemblies than $\mathrm{CHCl}_{3}$ as demonstrated by the presence of shorter urea-bonded aggregates in this solvent (FT-IR and SANS analyses, Figure S.1).

[27] M. J. Mayoral, C. Rest, J. Schellheimer, V. Stepanenko, G. Fernández, Chem. Eur. J. 2012, 18, 15607-15611.

[28] One could imagine that if the racemate gold complexes form mixtures of right-handed and left-handed helical assemblies in equal proportion, the enantiopure sergeant might insert preferentially into one of the two helices (diastereoselective recoginition). If the sergeants-and-soldiers assemblies preciptate then the observed ICD might be due the left- or right-handed helices formed by the gold complex alone. However, this hypothesis can be discarded because: i) no precipate is observed and ii) both the sergeants and soldiers contribute to the UV and CD spectra for the mixtures with $\chi$ sergeant $\geq 0.5$ (see Figure S.4).

[29] The ICD signal displayed by $\mathbf{1} \cdot \mathrm{AuPPh}_{3}:(\mathbf{S S}) \mathbf{3}$ is shifted to higher wavelength compared to $1 \cdot \mathrm{AuPC}_{\mathbf{3}}:(\mathbf{S S})-\mathbf{3}(5 \mathrm{~nm})$. This bathochromic shift is also observed in the UV spectra of the gold complexes and in that of the 1:1 mixtures of the gold complexes and (SS)-3 (Figure S.3).

[30] M. Raynal, F. Portier, P. W. N. M. van Leeuwen, L. Bouteiller, J. Am Chem. Soc. 2013, 135, 17687-17690. 